\title{
Maximum power point tracking techniques for photovoltaic systems: a comparative study
}

\author{
M. A. Abo-Sennah ${ }^{1}$, M. A. El-Dabah ${ }^{2}$, Ahmed El-Biomey Mansour ${ }^{3}$ \\ ${ }^{1}$ Department of Electrical Engineering, Faculty of Engineering, Al-Azhar University, Qena, Egypt \\ ${ }^{2,3}$ Department of Electrical Engineering, Faculty of Engineering, Al-Azhar University, Cairo, Egypt
}

\begin{tabular}{l}
\hline Article Info \\
\hline Article history: \\
Received Apr 17, 2020 \\
Revised Jun 17, 2020 \\
Accepted Jun 30, 2020 \\
\hline
\end{tabular}

\section{Keywords:}

Artificial intelligence (AI)

Bio-inspired (BI)

Classical techniques

MPPT techniques

Photovoltaic (PV)

Renewable energy resources

\begin{abstract}
Photovoltaic (PV) systems are one of the most important renewable energy resources (RER). It has limited energy efficiency leading to increasing the number of PV units required for certain input power i.e. to higher initial cost. To overcome this problem, maximum power point tracking (MPPT) controllers are used. This work introduces a comparative study of seven MPPT classical, artificial intelligence (AI), and bio-inspired (BI) techniques: perturb and observe $(\mathrm{P} \& \mathrm{O})$, modified perturb and observe (M-P\&O), incremental conductance (INC), fuzzy logic controller (FLC), artificial neural network (ANN), adaptive neuro-fuzzy inference system (ANFIS), and cuckoo search (CS). Under the same climatic conditions, a comparison between these techniques in view of some criteria's: efficiencies, tracking response, implementation cost, and others, will be performed. Simulation results, obtained using MATLAB/SIMULINK program, show that the MPPT techniques improve the lowest efficiency resulted without control. ANFIS is the highest efficiency, but it requires more sensors. CS and ANN produce the best performance, but CS provided significant advantages over others in view of low implementation cost, and fast computing time. $\mathrm{P} \& \mathrm{O}$ has the highest oscillation, but this drawback is eliminated using M-P\&O. FLC has the longest computing time due to software complexity, but INC has the longest tracking time.
\end{abstract}

This is an open access article under the CC BY-SA license.

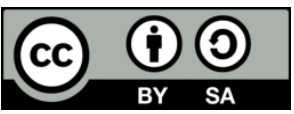

\section{Corresponding Author:}

M. A. El-Dabah,

Department of Electrical Engineering,

Al-Azhar University,

El Mokhayam El Daem Street, Nasr City, Cairo, Egypt.

Email:dr_mdabah@azhar.edu.eg

\section{INTRODUCTION}

Nowadays, renewable energy resources such as photovoltaic (PV) solar energy is one of the most free and friendly source compared to other traditional sources. PV is a static and nonlinear device converts the light (photon) energy directly into electricity and it can be represented as a current source model. The major problems of PV systems are the low conversion efficiency and non-linearity due to characteristics (I-V \& P-V curves) is strongly depended on atmospheric conditions (irradiance $(\mathrm{G})$, and temperature $(\mathrm{T})$ ) $[1,2]$. At the top (knee) of I-V curve, there is a point changes with $\mathrm{G}$ and $\mathrm{T}$ called maximum power point (MPP) at which the PV source should be operates to produce and transfer maximum power to the load regardless of variations in climatic conditions. A device can track this unique point called maximum power point tracking (MPPT), where it located between PV source and load. It comprises two essential components, DC-DC converter along with MPPT controller. Many MPPT techniques can be used to change the system operating point by controlling the duty cycle and generating a pulse to fire a switch of DC-DC converter [3]. 
Many researchers addressed a topic of MPPT techniques and the literature survey classified it into many types $[4,5]$ : conventional such as perturb and observe (P\&O) [6], incremental conductance (INC) [7, 8], artificial intelligence (AI) such as fuzzy logic controller (FLC) [3, 9-11], artificial neural network (ANN) [12, 13], adaptive neuro-fuzzy inference system (ANFIS) [14-16], hybrid techniques such as modified perturb and observe (M-P\&O) using FLC [17, 18], bio-inspired (BI) or meta-heuristic techniques such as cuckoo search (CS) [19, 20], and others. Papers [21-24] introduce the implementation of different techniques. Authors also study a comparison of different MPPT techniques based on conventional [25], artificial intelligence [26], both conventional and AI [27], and meta-heuristic [28].

The goal of this paper is to give a comparative study to find the best among seven proposed MPPT methods: perturb and observe (P\&O), incremental conductance (INC), fuzzy logic controller (FLC), artificial neural network (ANN), modified perturb and observe (M-P\&O), adaptive neoro-fuzzy inference system (ANFIS), and cuckoo search (CS) in view of 9 criteria's: MPPT efficiency, improved efficiency, MPPT error, different values of duty ratio, tracking time, steady state power oscillation, effect of irradiance and temperature on the PV voltage $\left(\mathrm{V}_{\mathrm{pv}}\right)$ and current $\left(\mathrm{I}_{\mathrm{pv}}\right)$, implementation cost, and the computing time. DC-DC buck converter was chosen in this paper as the interface between PV source and a resistive load.

MATLAB/SIMULINK program used to model and obtain results shows that the CS-technique based on meta-heuristic provided significant advantages over other proposed techniques i.e. considered the best, and the ANN-technique is similar to CS in most results. The AI-techniques like ANN, ANFIS, and FLC have the fastest tracking speed respectively, and ANFIS has the highest efficiency over other techniques. Conventional techniques like P\&O and INC are simple, but they suffer from high oscillation and slow tracking response respectively. FLC can be blended with P\&O to eliminate the oscillation around MPP. The following sections are organized as follows: Section 2 introduces the research method which explains the system description, mechanism of load matching and the proposed MPPT techniques. Section 3 presents the simulation results and discussion. Finally, the paper is concluded in section 4.

\section{RESEARCH METHOD}

\subsection{System description}

Figure 1 shows block diagram of the proposed stand-alone PV system consists of PV array, DC/DC buck converter controlled by MPPT controller, and resistive load. The PV array affect by irradiance $(\mathrm{G})$, and temperature $(\mathrm{T})$ to generate and transfer maximum power to the load. To achieve this goal, MPPT controller inserted between them to control the duty cycle and generate a pulse to fire the DC/DC converter switch i.e. to track MPP. Seven types of MPPT techniques are used to drive the system under seven levels of weather conditions acting as inputs of PV array during simulation stop time equal $0.7 \mathrm{~S}$. The controller acquires real-time operating parameters such as PV voltage and current $\left(\mathrm{V}_{\mathrm{PV}}, \mathrm{I}_{\mathrm{PV}}\right)$ or irradiance and temperature $(\mathrm{G}, \mathrm{T})$ depending on the control algorithm [1]. MATLAB/SIMULINK program is used to model and simulate the proposed system.

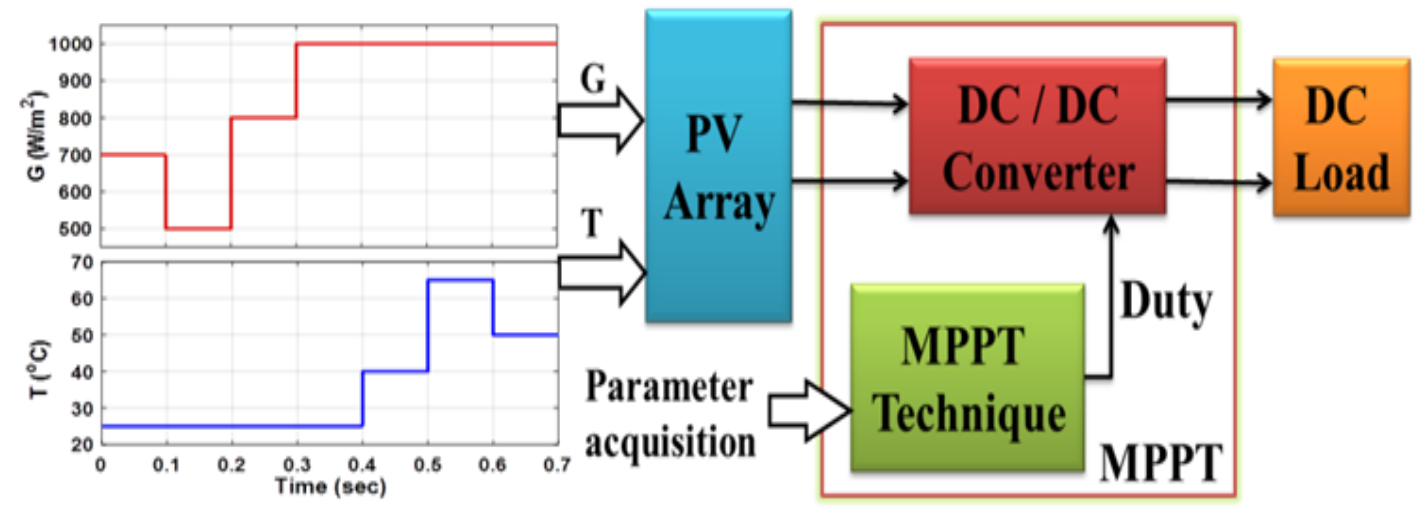

Figure 1. Description of proposed PV system with MPPT controller unit

\subsection{Mechanism of load matching for DC-DC buck converter}

When a fixed resistive load $\left(\mathrm{R}_{\mathrm{L}}\right)$ is directly connected to PV source, the operating point is determined by the intersection of I-V characteristics for both PV source and load depending on load value, as in Figure 2(a). Transferring maximum power to the load is performed by matching the internal source impedance with the load 
impedance. When load resistance $\left(\mathrm{R}_{\mathrm{L}}\right)$ is equal to a value called optimum resistance $\left(\mathrm{R}_{\mathrm{opt}}\right)$, load matching occurs [29]. The load resistance $\left(\mathrm{R}_{\mathrm{L}}\right)$ and the internal resistance of PV source $\left(\mathrm{R}_{\text {in }}\right)$ are described as:

$$
\mathrm{R}_{\mathrm{L}}=\frac{\mathrm{V}_{\mathrm{L}}}{\mathrm{I}_{\mathrm{L}}}, \quad \mathrm{R}_{\mathrm{in}}=\frac{\mathrm{V}_{\mathrm{mp}}}{\mathrm{I}_{\mathrm{mp}}}
$$

where: $\mathrm{V}_{\mathrm{L}}, \mathrm{I}_{\mathrm{L}}$ is the load voltage and current respectively. $\mathrm{V}_{\mathrm{mp}}, \mathrm{I}_{\mathrm{mp}}$ is voltage and current at MPP respectively.

DC-DC converter converts unregulated DC inputs into a controlled DC output. MPPT provides load matching and transfer maximum power by regulating the input voltage and by controlling the duty ratio (D). By neglecting the losses in the circuit, relations for a buck (step down) converter are:

$$
\frac{\mathrm{V}_{\mathrm{o}}}{\mathrm{V}_{\text {in }}}=\frac{\mathrm{I}_{\text {in }}}{\mathrm{I}_{\mathrm{o}}}=\frac{\mathrm{t}_{\mathrm{on}}}{\mathrm{T}_{\mathrm{S}}}=\mathrm{D}
$$

Input resistance of the converter can be calculated by knowing the input voltage and current. MPP capture for the buck converter will only be possible for $R_{L} \leq R_{M P P}$ values, as in Figure 2(b), as shown in (3) and (4) [30]. Characteristics of used PV module HC Solar Power HCP250P-24, 250-W are taken at standard test conditions STC $\left(1 \mathrm{kw} / \mathrm{m}^{2}, 25^{\circ} \mathrm{C}\right)$ and listed in Table 1 . The proposed $1-\mathrm{kw}$ PV array consists of 4 modules, ( 2 in series $* 2$ in parallel). Output (load) voltage is closed to be $48 \mathrm{~V}$. Designed parameter is summarized in Table 2 [11].

$$
\begin{aligned}
& \mathrm{R}_{\text {in }}=\frac{\mathrm{V}_{\text {in }}}{\mathrm{I}_{\text {in }}}=\frac{\mathrm{V}_{\mathrm{o}} / \mathrm{D}}{\mathrm{I}_{\mathrm{o}} \mathrm{D}}=\frac{\mathrm{V}_{\mathrm{o}} / \mathrm{I}_{\mathrm{o}}}{\mathrm{D}^{2}}=\frac{\mathrm{R}_{\mathrm{o}}}{\mathrm{D}^{2}}=\frac{\mathrm{R}_{\mathrm{L}}}{\mathrm{D}^{2}} \\
& D=\sqrt{\frac{R_{L}}{R_{\text {in }}}}
\end{aligned}
$$

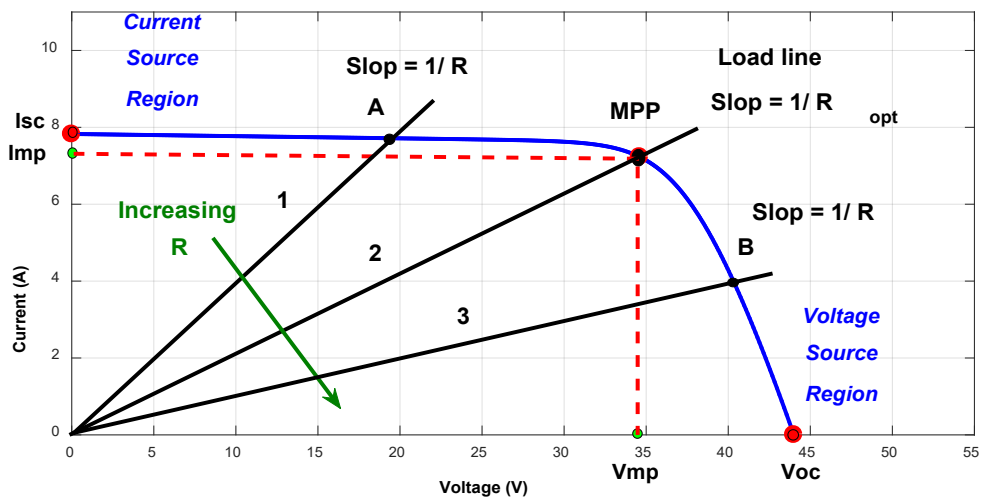

(a)

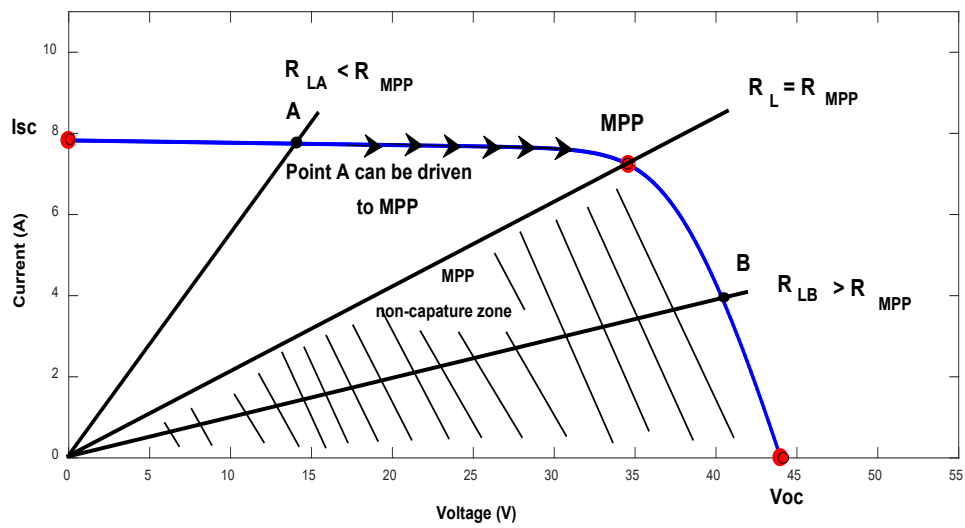

(b)

Figure 2. (a) Intersection of I-V curve and load line, (b) MPP capture for the buck converter 
Table 1. Characteristics of PV module at STC

\begin{tabular}{lll}
\hline Parameter & Symbol & Value \\
\hline Maximum power & Pmax & $250.158 \mathrm{~W}$ \\
Voltage at MPP & Vmp & $34.6 \mathrm{~V}$ \\
Current at MPP & Imp & $7.23 \mathrm{~A}$ \\
Open circuit voltage & Voc & $44 \mathrm{~V}$ \\
Short circuit current & Isc & $7.82 \mathrm{~A}$ \\
Cells per module & Ncell & 72 Cells \\
\hline
\end{tabular}

Table 2. Summary of converter parameters and load value

\begin{tabular}{lll}
\hline Parameter & Symbol & Value \\
\hline Maximum input voltage & $\mathrm{V}_{\text {inm }}$ & $69.2 \mathrm{~V}$ \\
Maximum output voltage & $\mathrm{V}_{\mathrm{om}}$ & $48 \mathrm{~V}$ \\
Maximum input current & $\mathrm{I}_{\mathrm{inm}}$ & $14.46 \mathrm{~A}$ \\
Maximum output current & $\mathrm{I}_{\mathrm{om}}$ & $20.8465 \mathrm{~A}$ \\
Duty ratio at maximum power output & $\mathrm{D}_{\mathrm{mp}}$ & 0.6936 \\
Switching frequency & $\mathrm{f}_{\mathrm{s}}$ & $5 \mathrm{KHZ}$ \\
Input capacitor filter & $\mathrm{C}_{\text {in }}$ & $800 \mu \mathrm{F}$ \\
Output inductor filter & $\mathrm{L}$ & $353 \mu \mathrm{H}$ \\
Output capacitor filter & $\mathrm{C}_{\mathrm{o}}$ & $400 \mu \mathrm{F}$ \\
Optimum input (Internal) resistance & $\mathrm{R}_{\text {in }}$ & $4.786 \Omega$ \\
Optimum output (Load) resistance & $\mathrm{R}_{\mathrm{L}}$ & $2.303 \Omega$ \\
\hline
\end{tabular}

\subsection{Maximum power point tracking techniques}

This sub-section has seven tracking techniques, which has the ability to drive the PV system to find the optimum operating point under changing atmospheric conditions.

\subsubsection{Perturb and observe $(\mathrm{P} \& O)$ technique}

$\mathrm{P} \& \mathrm{O}$ method is one of hill-climbing algorithms that depend on moving the operating point of the PV array in the direction of which the power is increasing. Its concept is based on that: On the P-V curve, the change in PV power is equal to zero at MPP $\left(\Delta \mathrm{P}_{\mathrm{PV}}=0\right)$. Flowchart of the $\mathrm{P} \& \mathrm{O}$ algorithm is illustrated in Figure $3[6,10]$. It operates with fixed step-size by periodically perturbing (incrementing or decrementing) the PV array voltage and comparing $\mathrm{P}(\mathrm{k}+1)$ with the previous perturbation $\mathrm{P}(\mathrm{k})$. This cycle is repeated until reaching the MPP [25]. P\&O algorithm has two inputs: PV voltage $\left(\mathrm{V}_{\mathrm{PV}}\right)$, and current $\left(\mathrm{I}_{\mathrm{PV}}\right)$, and one output that is duty ratio (D). This method has simple implementation and low cost, but it has disadvantages of the oscillations around MPP, also under rapidly changing atmospheric conditions it may track MPP in the wrong direction $[14,25]$.

\subsubsection{Incremental conductance (INC) technique}

INC algorithm also based on the hill climbing principle. It is based on the derivative of PV power with respect to PV voltage which is equal to zero at MPP, negative on the right and positive on the left of it [27]. Flowchart of INC algorithm is illustrated in Figure 4 [6]. Since:

$$
\frac{d P}{d V}=\frac{d(I V)}{d V}=I+V \frac{d I}{d V}=I+V \frac{\Delta I}{\Delta V}
$$

From the relations above we have:

$$
\begin{aligned}
& \frac{\Delta \mathrm{I}}{\Delta \mathrm{V}}=\frac{-\mathrm{I}}{\mathrm{V}} \text { at MPP } \\
& \frac{\Delta \mathrm{I}}{\Delta \mathrm{V}}>\frac{-\mathrm{I}}{\mathrm{V}} \text { at left of MPP } \\
& \frac{\Delta \mathrm{I}}{\Delta \mathrm{V}}<\frac{-\mathrm{I}}{\mathrm{V}} \text { at right of MPP }
\end{aligned}
$$

INC depends on measuring and comparing the incremental conductance $(\Delta \mathrm{I} / \Delta \mathrm{V})$, and instantaneous conductance (I/V) of PV [7]. When they are equal, MPP is reached. INC-MPPT has two inputs: PV voltage $\left(\mathrm{V}_{\mathrm{pv}}\right)$, and current $\left(\mathrm{I}_{\mathrm{pv}}\right)$ and one output duty ratio (D). This technique less oscillation than P\&O-technique, but it has disadvantage of slows response for MPP [14]. 


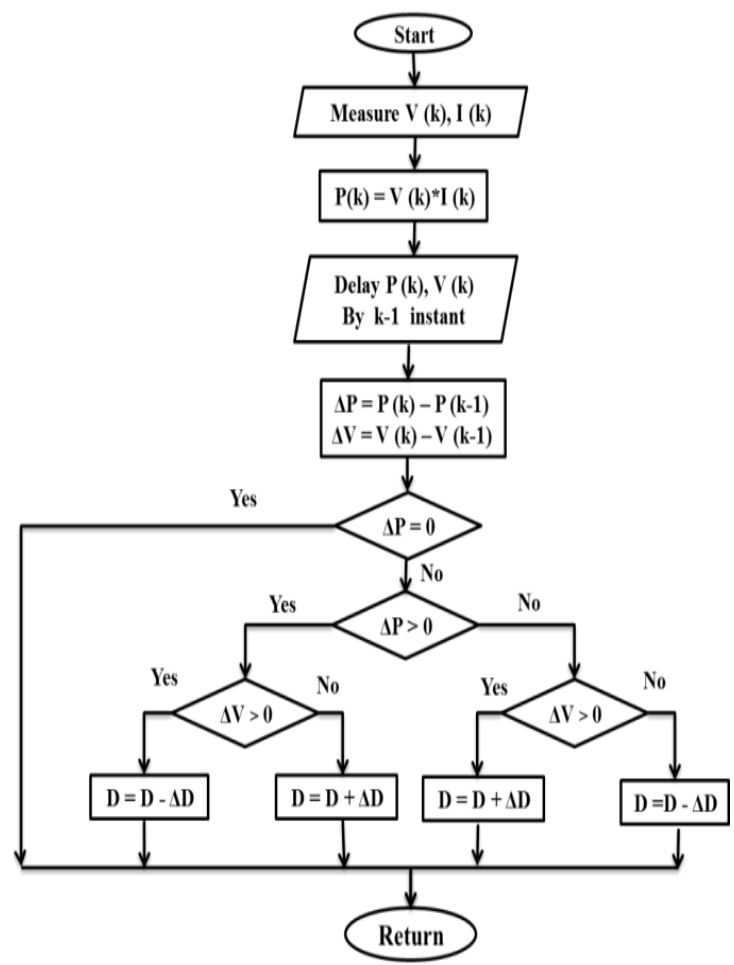

Figure 3. Flowchart of the $\mathrm{P} \& \mathrm{O}$ algorithm

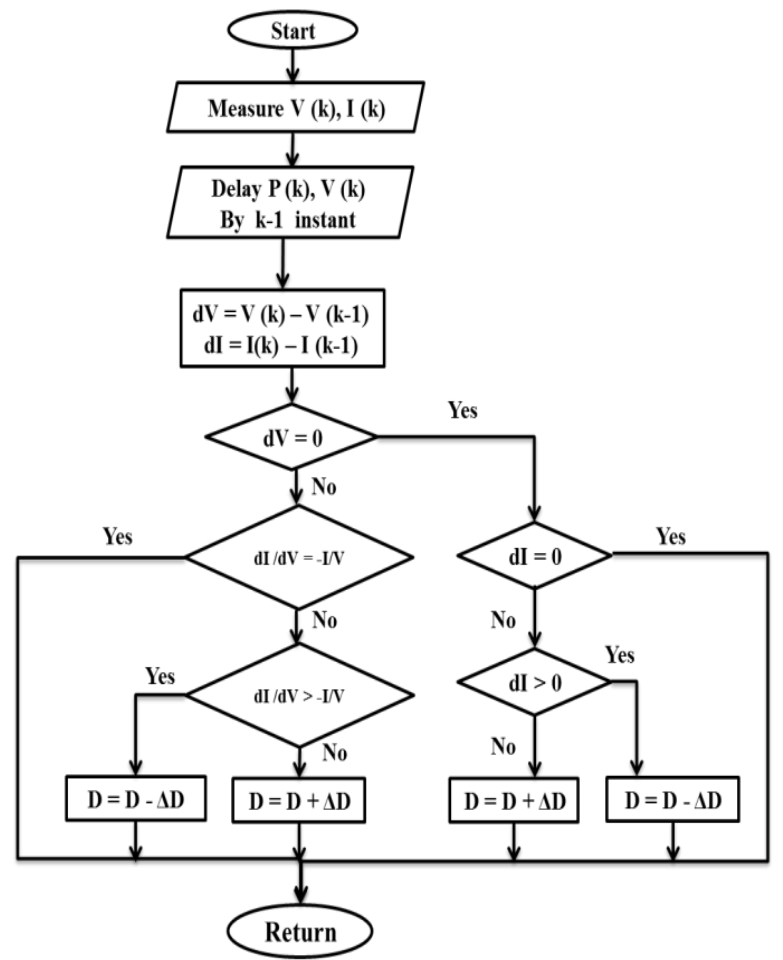

Figure 4. Flowchart of the INC algorithm

\subsubsection{Fuzzy logic controller (FLC) technique}

Fuzzy logic is one of artificial intelligence (AI) techniques that simulate human-like decisions in control. It deals with noisy or missing input information, but it does not need an accurate mathematical model [26]. Fuzzification, inference engine, and defuzzification are the three components of typical fuzzy logic [3]. In the first process, crisp sets (numerical inputs) are converted to fuzzy sets (linguistic variables) based on a membership function $(\mathrm{MF})$. PV voltage $\left(\mathrm{V}_{\mathrm{pv}}\right)$ and current $\left(\mathrm{I}_{\mathrm{pv}}\right)$ can be measured as input variables and the power can be calculated, $\Delta \mathrm{P}(\mathrm{k})$ and $\Delta \mathrm{V}(\mathrm{k})$ are determined as follows:

$$
\begin{aligned}
& \Delta \mathrm{P}(\mathrm{k})=\mathrm{P}(\mathrm{k})-\mathrm{P}(\mathrm{k}-1) \\
& \Delta \mathrm{V}(\mathrm{k})=\mathrm{V}(\mathrm{k})-\mathrm{V}(\mathrm{k}-1)
\end{aligned}
$$

The two input variables to fuzzy controller are: error (E) which represents the slope of P-V curve and the change in error (CE) which expresses the moving direction of operating point, and one output change in duty ratio $(\Delta \mathrm{D})$, then it will be added to the previous duty cycle to determine the final duty (D) [9], where:

$$
\begin{aligned}
& \mathrm{E}(\mathrm{k})=\frac{\Delta \mathrm{P}(\mathrm{k})}{\Delta \mathrm{V}(\mathrm{k})}=\frac{\mathrm{P}(\mathrm{k})-\mathrm{P}(\mathrm{k}-1)}{\mathrm{V}(\mathrm{k})-\mathrm{V}(\mathrm{k}-1)} \\
& \mathrm{CE}(\mathrm{k})=\mathrm{E}(\mathrm{k})-\mathrm{E}(\mathrm{k}-1)
\end{aligned}
$$

Seven triangular $\mathrm{MF}_{\mathrm{S}}$ denoted by: negative big (NB), negative medium (NM), negative small (NS), zero (ZE), positive big (PB), positive medium (PM), and positive small (PS) [27] is used for both inputs and output, with range $(-200,200),(-0.8,0.8)$, and $(-0.001,0.001)$ respectively as in Figure 5 . The number, type and range of the MF are chosen by previous knowledge and/or experimental data from the PV system [26]. 49 fuzzy rules with the form IF-THEN shown in Table 3 [10] are applied to the fuzzy sets to determine the output. Mamdani fuzzy interface system (Mamdani-FIS) is used to perform the fuzzy inference process. Converting the linguistic fuzzy sets back to the crisp output using center of gravity (COG) defuzzification technique is the last process. Figure 6 shows the Simulink model for fuzzy controller. This method is a high powerful controller [14], and it can be blended with conventional techniques. Higher number of MFS affects the output accuracy, but it increases the complexity and the computing time [26]. 

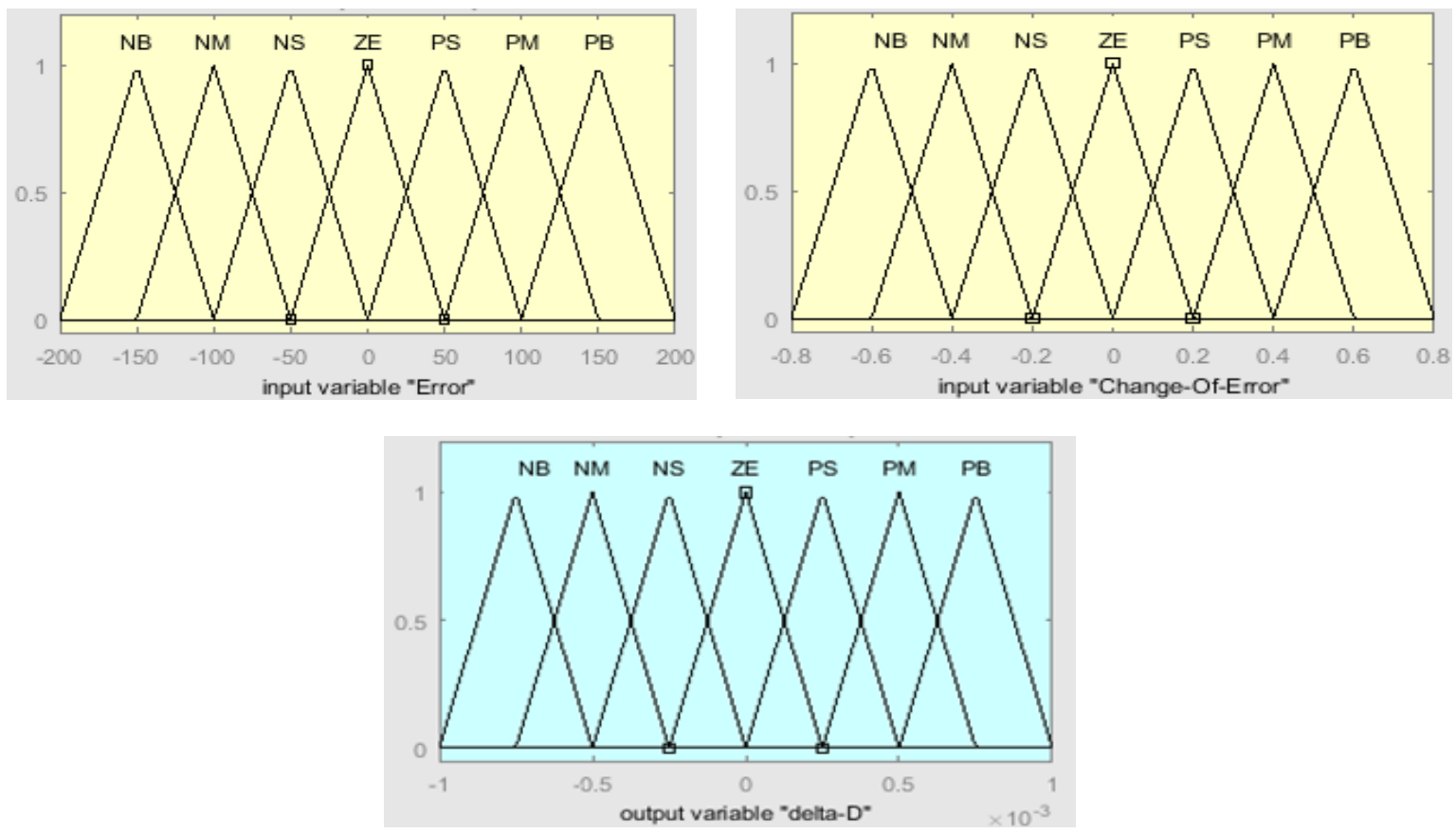

Figure 5. Membership function of E (k), CE (k), and delta-D

Table 3. Fuzzy control rules

\begin{tabular}{|c|c|c|c|c|c|c|c|}
\hline $\mathrm{E} \quad \mathrm{CE}$ & NB & NM & NS & ZE & PS & PM & PB \\
\hline NB & NB & NB & NB & $\mathrm{NB}$ & $\mathrm{NM}$ & NS & ZE \\
\hline $\mathrm{NM}$ & NB & NB & $\mathrm{NM}$ & $\mathrm{NM}$ & NS & ZE & PS \\
\hline NS & NB & NM & NS & NS & ZE & PS & PM \\
\hline $\mathrm{ZE}$ & NB & NM & NS & $\mathrm{ZE}$ & PS & PM & PB \\
\hline PS & NM & NS & ZE & PS & PS & PM & PB \\
\hline PM & NS & $\mathrm{ZE}$ & PS & PM & PM & PB & PB \\
\hline PB & $\mathrm{ZE}$ & PS & PM & PB & PB & PB & PB \\
\hline
\end{tabular}

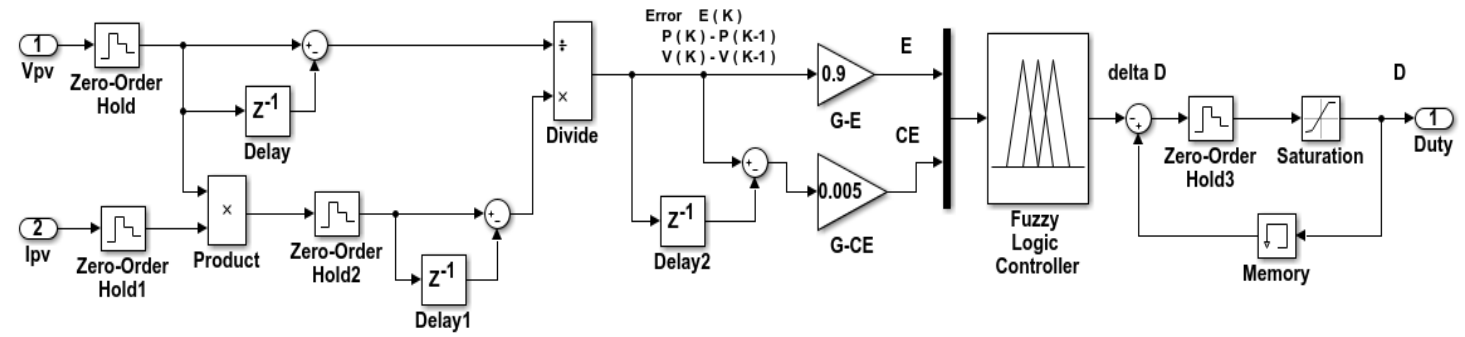

Figure 6. Simulink model of fuzzy controller

\subsubsection{Artificial neural network (ANN) technique}

Artificial neural network is one of powerful artificial intelligence (AI) techniques that simulate the human biological neural networks behavior. It is an information-processing model [12]. ANNs are consists of a large number of simple elements called neurons, operating in parallel and working to solve problems. This technique is based on a comparison of the output and the target, until the output of the network matches the target. So, many input/ target pairs are needed for training.

ANN is formed from 3 layers, as illustrated in Figure 7: input, hidden and output layer. Input layer receives inputs and spreads them to the neurons of hidden layer. Output layer produces the final ANN output. Hidden layer performs the intermediate calculations from input to output. Structure is chosen after several tests to increase the accuracy [26]. 


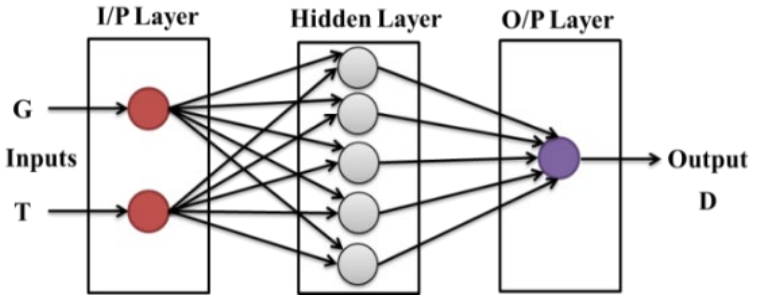

Figure 7. ANN Structure

Irradiance $(\mathrm{G})$ and temperature (T) are selected as non-electrical inputs [13] with 2 neurons in the input layer and transmitted to hidden layer with 5 neurons; the duty ratio (D) is the output. The input sample data points were collected to train the network. $\mathrm{G}$ is starting from 50 to $1000 \mathrm{~W} / \mathrm{m}^{2}$ in steps of $50 \mathrm{~W} / \mathrm{m}^{2}$ at constant $25^{\circ} \mathrm{C}$. Also, $\mathrm{T}$ is starting at 20 to $75^{\circ} \mathrm{C}$ in steps of $5^{\circ} \mathrm{C}$ at constant $1000 \mathrm{~W} / \mathrm{m}^{2}$. Figure 8 shows the mean square error (MSE) curve during off-line training using Levenberg-Marquardt backpropagation algorithm, where there are 3 parts of data, $70 \%$ for training, $15 \%$ for validation, and $15 \%$ for testing. The smaller the MSE is, the better the performance $[12,26]$. This method has a quick response, and less oscillation compared to fuzzy controller. ANN learns and does not need reprogramming process. Black box working and slow training are the main weaknesses of the ANN $[13,14]$.

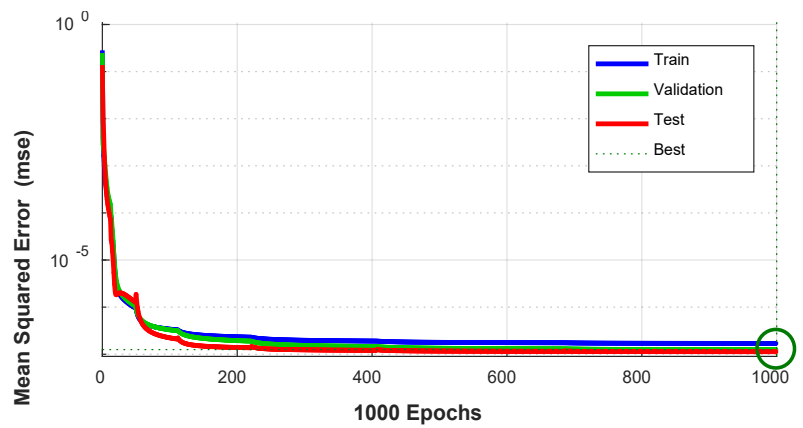

Figure 8. Mean square error during training

\subsubsection{Adaptive neuro-fuzzy inference system (ANFIS) technique}

Neuro-fuzzy system is an artificial intelligence (AI) and supervised machine-learning technique used in nonlinear applications. It based on the architecture and functions of neural network and fuzzy controller into one technique, so it used to overcome the drawbacks of them and to integrate the advantages of two AI-techniques [14]. For MPPT, ANFIS-technique operates by Sugeno fuzzy inference system (SugenoFIS) because it is more efficient where ANFIS has twofold (ANN and FLC). ANN is the first fold comprises (collection of data, training, testing, and validation), and FLC is the second fold comprises (fuzzification, inference, rules, and defuzzification) [15]. This technique creates a fuzzy system and has network-type structure like neural network [16].

In this work, ANFIS system has two inputs ( $G$ and $T)$, with 3 gaussian membership functions for each one termed as low, medium, and high, as in Figure 9(a) with nine rules that can follow the conditions. Output of ANFIS system is the crisp value of PV current at MPP $\left(\mathrm{I}_{\mathrm{mp}}\right)$, where it compared with the actual output current $\left(\mathrm{I}_{\mathrm{pv}}\right)$. Outcome is given to PI controller as error value to generate control signals as in Figure 9(b) Training data set for ANFIS is done by varying the two inputs in off-line using MATLAB toolbox. ANFIS-technique has high power efficiency and quick response for tracking MPP, and low computing time [14].

\subsubsection{Modified perturb and observe (M-P\&O) technique}

The conventional $\mathrm{P} \& \mathrm{O}$ algorithm is run with a fixed step-size. It has main limitation in the oscillation at steady-state [22]. M-P\&O technique is based on the standard P\&O, and modified using FLC to provide variable step-size in order to improve the trade-off between steady-state and dynamic state performance. It can be implemented either a duty-ratio control where the power is measured every PWM cycle, or reference voltage control where a PI-controller is needed to adjust the duty ratio $[17,18]$.

Maximum power point tracking techniques for photovoltaic systems: a comparative ... (M. A. Abo-Sennah) 
PV voltage and current can be measured to calculate the fuzzy input variables, the change in PV power $\left(\Delta \mathrm{P}_{\mathrm{PV}}\right)$, and current $\left(\Delta \mathrm{I}_{\mathrm{PV}}\right)$. The output variable is the change in step-size $(\Delta \mathrm{S})$ which is sent as input to the $\mathrm{P} \& \mathrm{O}$ and defuzzified using center of gravity $(\mathrm{COG})$ method. Flow chart of $\mathrm{M}-\mathrm{P} \& \mathrm{O}$ with variable step-size is in Figure 10 [18]. Five triangular $\mathrm{MF}_{\mathrm{S}}$ is used for both inputs and output, with range $(-200,200)$, $(-12,12)$, and $(-0.4,0.4)$ for $\left(\Delta \mathrm{P}_{\mathrm{PV}}\right),\left(\Delta \mathrm{I}_{\mathrm{PV}}\right)$, and $(\Delta \mathrm{S})$ respectively. To perform the fuzzy inference process, 25 fuzzy rules shown in Table 4 are applied using Mamdani-FIS [17, 18].

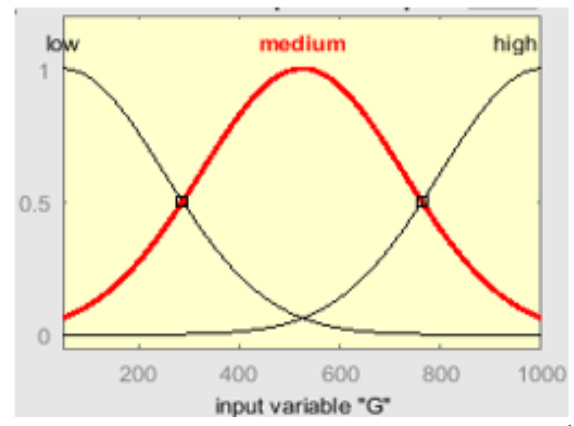

(a)
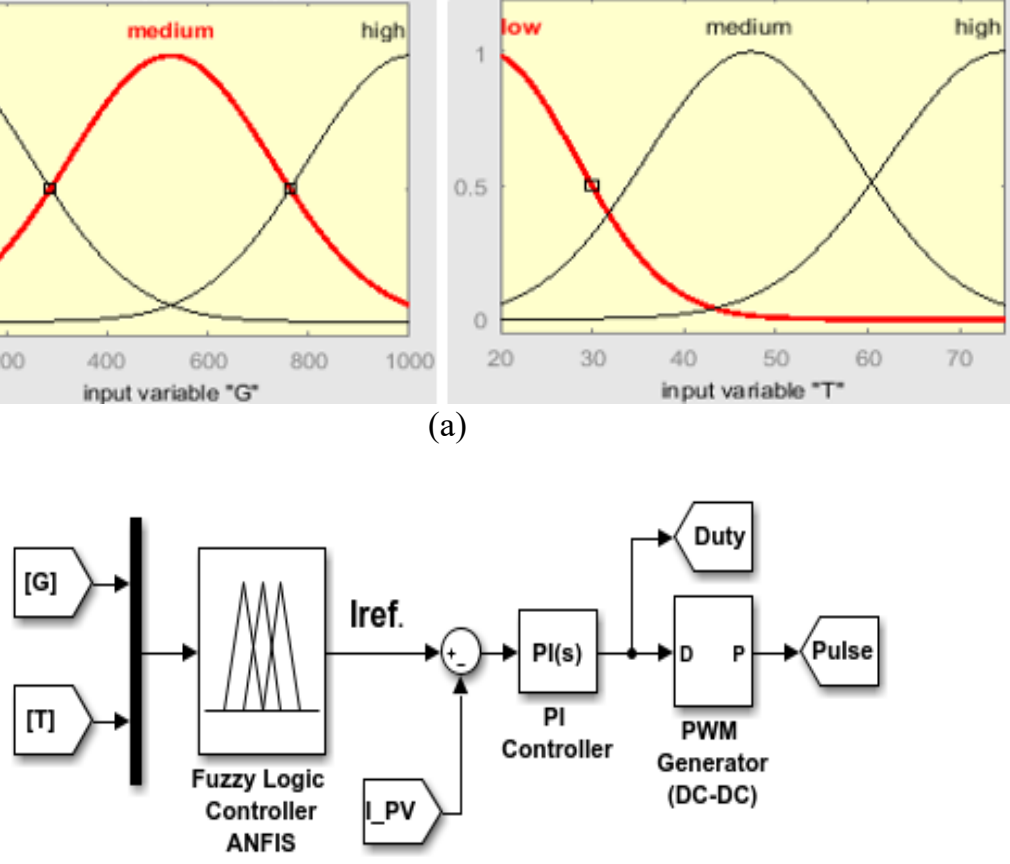

(b)

Figure 9. ANFIS (a) MFs of irradiance and temperature, (b) simulink model of control system

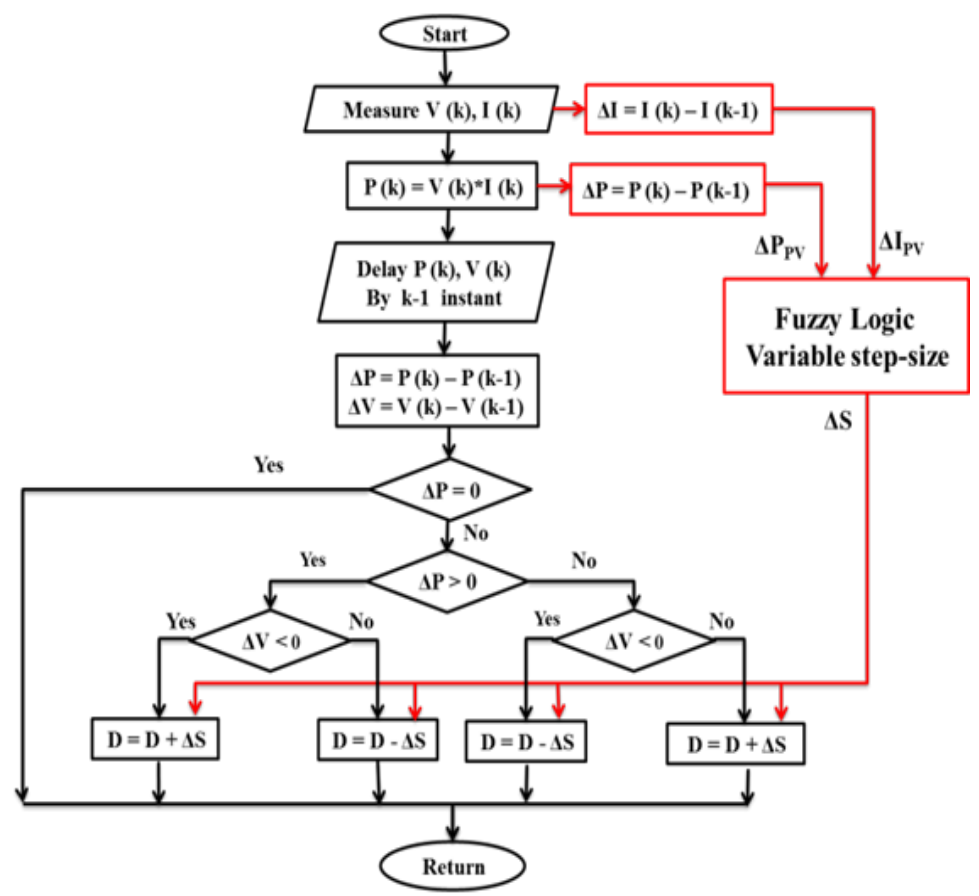

Figure 10. Flow chart of M-P\&O technique 


\begin{tabular}{|c|c|c|c|c|c|}
\hline$\underset{\triangle \mathrm{PPV}}{\Delta \mathrm{IPV}}$ & NB & NS & ZE & PS & PB \\
\hline NB & NB & NS & ZE & ZE & PS \\
\hline NS & NS & ZE & ZE & PS & PS \\
\hline ZE & NS & ZE & ZE & PS & PB \\
\hline PS & ZE & ZE & PS & PS & PB \\
\hline PB & ZE & PS & PS & PB & PB \\
\hline
\end{tabular}

\subsubsection{Cuckoo search (CS) technique}

Cuckoo search is one of the best optimization meta-heuristic techniques and become popular among the intelligent algorithms [28]. It drives PV system with high efficiency and quick response for MPP [19, 20]. This technique inspired by the parasitic behavior and aggressive reproduction strategy of cuckoo birds, where they lay eggs in communal nests and may remove others' eggs to increase the hatching probability of their own eggs [19]. CS-technique depends on 3 rules: each cuckoo should lays only one egg at a time in randomly selected nest, the best nest in the first iteration with high quality of eggs (i.e., with the best values of the objective function) will carry over to the next generation, and the egg laid by a cuckoo in another nest can be discovered by the host bird with a probability $\mathrm{Pa}$ where $(0<\mathrm{Pa}<1)$. Searching process for the best nest of a host bird occurs in a random form. It can be modeled on mathematical function called Lévy flight. Flowchart of CS is illustrated in Figure 11 [20].

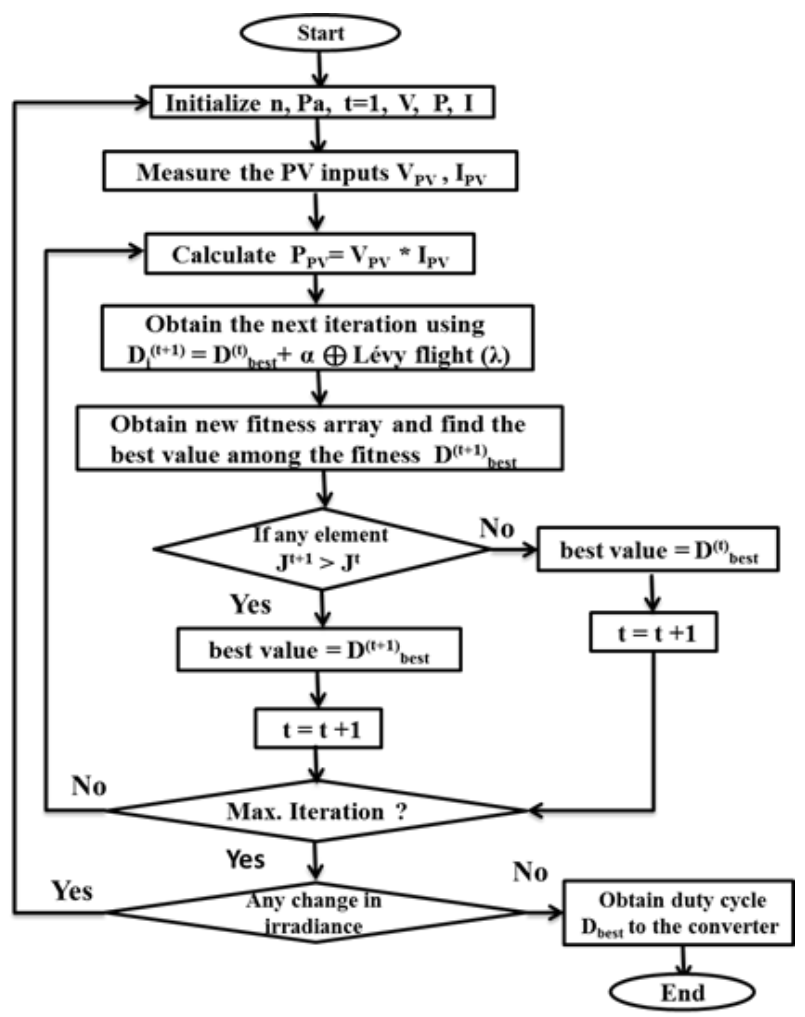

Figure 11. Flow chart of CS technique

In this method, $\mathrm{PV}$ voltage $\left(\mathrm{P}_{\mathrm{PV}}\right)$ and current $\left(\mathrm{I}_{\mathrm{PV}}\right)$ are measured and acts as inputs. The duty cycle (D) is the output and can be updated based on Lévy flight by the following [5, 28]:

$$
\mathrm{D}_{\mathrm{i}}^{(\mathrm{t}+1)}=\mathrm{D}^{(\mathrm{t})}{ }_{\text {best }}+\alpha \oplus \text { Lévy flight }(\lambda)
$$

where: $D_{\text {best }}{ }^{(t)}$ are samples /eggs or the best duty cycle among the fitness, $i$ is the sample number, $t$ is the number of iteration, $\alpha$ is the step-size ( $\alpha>0$ and assumed that $\alpha=1$ ), the product $\oplus$ means entry wise multiplications. The value of $\alpha$ can be calculated as: 


$$
\alpha=\alpha_{0}\left(\mathrm{x}_{\mathrm{j}}^{(\mathrm{t})}-\mathrm{X}_{\mathrm{i}}^{(\mathrm{t})}\right)
$$

The step length is drawn from le'vy distribution according to power law, where:

$$
\operatorname{Lévy}(\lambda) \approx \mathrm{u}=\mathrm{L}^{-\lambda} \quad \text { where }(1<\lambda<3)
$$

\section{RESULTS AND DISCUSSIONS}

\subsection{Results}

This section shows comparison results and waveforms for 7 proposed techniques at steady state, and dynamic state at the starting of each level of 7 climatic conditions. Statistical results and analysis are listed in tables.

\subsection{Discussion}

$\mathrm{I}-\mathrm{V} \& \mathrm{P}-\mathrm{V}$ characteristic curves of PV array shown in Figure 12 (see appendix) compare the operating points without any control (black) with optimum ones at MPPT (red). It appears that the PV system without any control does not operate at ideal (optimum) operating points, i.e. it operates at low power efficiency. Low resultant efficiency without control is improved from $50.6 \%$ to $99.9 \%$ by seven proposed MPPT techniques (P\&O, INC, FLC, ANN, M-P\&O, ANFIS, and CS) with a small range of error as shown in Figure 13 (see appendix) and Table 5. The seven proposed techniques work very efficiently from $99.98 \%$ to $99.89 \%$. ANFIS-technique is the highest energy efficiency up to $99.98 \%$, but ANN and CS techniques work with $99.89 \%$. These values agree with high efficiency in $[14,20]$ for ANFIS and CS. In [26] FLC is lower efficiency than ANN, but results of FLC is higher than ANN in this work. Duty ratio is the output of MPPT controller, and then it feds to fire the switch of DC/DC converter by pulse width modulation (PWM). From the results of duty ratio shown in Figure 14 (see appendix) and Table 6, the generated duty value of CS and ANN techniques are the best compared to other techniques and approximately equal the optimum.

\begin{tabular}{|c|c|c|c|c|c|c|c|c|c|}
\hline Atmospheric conditions & $\begin{array}{c}\mathrm{G}\left(\mathrm{W} / \mathrm{m}^{2}\right) \\
\mathrm{T}\left({ }^{\circ} \mathrm{C}\right)\end{array}$ & $\begin{array}{l}700 \\
25\end{array}$ & $\begin{array}{c}500 \\
25\end{array}$ & $\begin{array}{c}800 \\
25\end{array}$ & $\begin{array}{c}1000 \\
25\end{array}$ & $\begin{array}{c}1000 \\
40\end{array}$ & $\begin{array}{c}1000 \\
65\end{array}$ & $\begin{array}{c}1000 \\
50\end{array}$ & 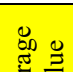 \\
\hline \multicolumn{2}{|c|}{$P_{\max }(W)$ "Theoretical" } & 714.8 & 515.2 & 812 & 1000.632 & 941.2 & 840.8 & 901.2 & $\bar{\psi}$ \\
\hline Direct & $\mathrm{P}_{\mathrm{pv}}(\mathrm{W})$ & 272 & 139.7 & 354.1 & 549.7 & 559.1 & 574.5 & 565.3 & ----- \\
\hline Without MPPT & $\eta_{\text {without-MPРT }}(\%)$ & 38.05 & 27.12 & 43.61 & 55 & 59.4 & 68.33 & 62.73 & 50.6 \\
\hline \multirow{4}{*}{ P\&O } & $\mathrm{P}_{\mathrm{pv}}(\mathrm{W})$ & 714.5 & 514.9 & 811.5 & 1000.1 & 941.2 & 840.5 & 900.8 & ------ \\
\hline & $\eta_{\text {MPPT }}(\%)$ & 99.95 & 99.94 & 99.93 & 99.94 & 100 & 99.96 & 99.95 & 99.95 \\
\hline & Improved efficiency (\%) & 61.9 & 72.82 & 56.32 & 44.94 & 40.6 & 31.63 & 37.22 & 49.35 \\
\hline & MPPT Error (\%) & 0.042 & 0.058 & 0.062 & 0.053 & 0 & 0.036 & 0.044 & 0.042 \\
\hline \multirow{4}{*}{ INC } & $\mathrm{P}_{\mathrm{pv}}(\mathrm{W})$ & 714.8 & 514.9 & 812 & 1000.3 & 940.8 & 840.6 & 900.8 & ----- \\
\hline & $\eta_{\text {MPPT }}(\%)$ & 100 & 99.94 & 100 & 99.96 & 99.95 & 99.97 & 99.95 & 99.96 \\
\hline & Improved efficiency (\%) & 61.95 & 72.82 & 56.39 & 44.96 & 40.55 & 31.64 & 37.22 & 49.36 \\
\hline & MPPT Error (\%) & 0 & 0.058 & 0 & 0.033 & 0.042 & 0.024 & 0.044 & 0.029 \\
\hline \multirow{4}{*}{ FLC } & $\mathrm{P}_{\mathrm{pv}}(\mathrm{W})$ & 714.7 & 515 & 811.8 & 1000.2 & 940.9 & 840.6 & 901.2 & ---- \\
\hline & $\eta_{\text {MPPT }}(\%)$ & 99.98 & 99.96 & 99.97 & 99.95 & 99.96 & 99.97 & 100 & 99.97 \\
\hline & Improved efficiency $(\%)$ & 61.93 & 72.84 & 56.36 & 44.95 & 40.56 & 31.64 & 37.27 & 49.37 \\
\hline & MPPT Error (\%) & 0.014 & 0.039 & 0.025 & 0.043 & 0.032 & 0.023 & 0 & 0.025 \\
\hline \multirow{4}{*}{$\mathbf{A N N}$} & $\mathrm{P}_{\mathrm{pv}}(\mathrm{W})$ & 714.3 & 514.8 & 811.1 & 999.3 & 940.3 & 840.2 & 900.1 & ----- \\
\hline & $\eta_{\text {MPPT }}(\%)$ & 99.93 & 99.92 & 99.88 & 99.86 & 99.90 & 99.92 & 99.87 & 99.89 \\
\hline & Improved efficiency (\%) & 61.88 & 72.80 & 56.27 & 44.86 & 40.5 & 31.59 & 37.14 & 49.29 \\
\hline & MPPT Error (\%) & 0.070 & 0.078 & 0.011 & 0.133 & 0.096 & 0.071 & 0.122 & 0.083 \\
\hline \multirow{4}{*}{ M-P\&O } & $\mathrm{P}_{\mathrm{pv}}(\mathrm{W})$ & 714.7 & 514.7 & 811.8 & 1000 & 941 & 840.7 & 900.8 & ----- \\
\hline & $\eta_{\text {MPPT }}(\%)$ & 99.98 & 99.90 & 99.97 & 99.93 & 99.97 & 99.98 & 99.95 & 99.95 \\
\hline & Improved efficiency $(\%)$ & 61.93 & 72.78 & 56.36 & 44.93 & 40.57 & 31.65 & 37.22 & 49.34 \\
\hline & MPPT Error (\%) & 0.014 & 0.097 & 0.025 & 0.063 & 0.021 & 0.012 & 0.044 & 0.039 \\
\hline \multirow{4}{*}{ ANFIS } & $\mathrm{P}_{\mathrm{pv}}(\mathrm{W})$ & 714.8 & 515 & 811.9 & 1000.1 & 941.2 & 840.7 & 901.2 & ----- \\
\hline & $\eta_{\text {MPPT }}(\%)$ & 100 & 99.96 & 99.98 & 99.94 & 100 & 99.98 & 100 & 99.98 \\
\hline & Improved efficiency (\%) & 61.95 & 72.84 & 56.37 & 44.94 & 40.6 & 31.65 & 37.27 & 49.37 \\
\hline & MPPT Error (\%) & 0 & 0.039 & 0.012 & 0.053 & 0 & 0.012 & 0 & 0.017 \\
\hline \multirow{4}{*}{ CS } & $\mathrm{P}_{\mathrm{pv}}(\mathrm{W})$ & 714.3 & 514.8 & 811.1 & 999.3 & 940.3 & 840.2 & 900.1 & ----- \\
\hline & $\eta_{\text {MPPT }}(\%)$ & 99.93 & 99.92 & 99.88 & 99.86 & 99.90 & 99.92 & 99.87 & 99.89 \\
\hline & Improved efficiency $(\%)$ & 61.88 & 72.80 & 56.27 & 44.86 & 40.5 & 31.59 & 37.14 & 49.29 \\
\hline & MPPT Error (\%) & 0.070 & 0.078 & 0.011 & 0.133 & 0.096 & 0.071 & 0.122 & 0.083 \\
\hline
\end{tabular}

Table 5. Results and efficiency comparison among MPPT techniques 
AI-techniques have tracking time smaller than the conventional ones, where it is $0.005,0.005,0.006$ and $0.007 \mathrm{~S}$ in case of CS, ANN, ANFIS and FLC respectively, as results in Table 7. These results are better than results in [20] for CS, [26] for FLC \& ANN, and the comparison in [14]. INC has the longest time equal $0.015 \mathrm{~S}$. M-P\&O technique (at $500 \mathrm{~W} / \mathrm{m}^{2}, 25^{\circ} \mathrm{C}$ ) needs a long time to reach MPP up to $0.034 \mathrm{~S}$.

$\mathrm{CS}, \mathrm{ANN}$ and M-P\&O have no oscillation, so they introduce the best results in view of this criterion. $\mathrm{P} \& \mathrm{O}$ has high oscillation because it works with fixed step-size, but this drawback was eliminated for M-P\&O by using fuzzy controller to provide variable step-size [17]. For the conventional techniques, P\&O has oscillations over than INC [14], but it has smaller tracking time compared to INC-technique.

Based on voltage and current waveforms in Figure 15 (see appendix), it's clear that under variable irradiance levels and fixed temperature, array current affected by irradiance, while voltage is approximately constant (change slightly). Under variable temperature levels and fixed irradiance, array current is approximately constant, while voltage affected by temperature. These curves support the influence of irradiance and temperature on PV characteristics [26].

Comparison in view of implementation cost depends on software and hardware requirements for each technique. It is based also on some factors such as knowing the type of circuitry, level of software complexity, number and type of required sensors. Analog domain and digital domain are the two types of implementation modes; they use continuous time and states in discrete time respectively. Analog techniques are simpler and cheaper than digital techniques, while digital circuitry are most widely used that require microcontroller and an advanced level of programming knowledge. Sensors are used to measure the value of some variables such as current, voltage and in some cases the level of irradiance, temperature. Voltage sensors are generally cheaper than current sensors, while irradiance and temperature sensors are expensive and uncommon [31].

Authors in [21-24] introduce the implementation of proposed technique, and [26, 31] have a comparison of required sensors, complexity, and implementation cost. Based on these literatures, Table 8 summarizes the comparison in view of implementation cost and computing time for proposed technique in this work. The ANFIS and ANN respectively are more expensive than other proposed techniques because irradiance and temperature sensors were required, while ANFIS requires an additional current sensor according this work. Software complexity affects the time required to simulation, so FLC, M-P\&O, and ANFIS require time longer than other techniques because the number of membership functions effects on it [26]. CS is the fastest technique for simulation which requires 37 seconds, so it is the best technique in this criterion.

Table 6. Results and comparison of duty ratio among proposed techniques

\begin{tabular}{cccccccc}
\hline $\mathrm{G}\left(\mathrm{W} / \mathrm{m}^{2}\right)$ & 700 & 500 & 800 & 1000 & 1000 & 1000 & 1000 \\
$\mathrm{~T}\left({ }^{\circ} \mathrm{C}\right)$ & 25 & 25 & 25 & 25 & 40 & 65 & 50 \\
\hline Duty ratio "Theory" & 0.577 & 0.487 & 0.618 & 0.694 & 0.718 & 0.762 & 0.734 \\
$\mathrm{P} \& \mathrm{O}$ & 0.578 & 0.486 & 0.623 & 0.696 & 0.719 & 0.767 & 0.735 \\
$\mathrm{INC}$ & 0.579 & 0.488 & 0.620 & 0.695 & 0.720 & 0.765 & 0.738 \\
$\mathrm{FLC}$ & 0.579 & 0.487 & 0.620 & 0.695 & 0.720 & 0.765 & 0.739 \\
$\mathrm{ANN}$ & 0.576 & 0.486 & 0.619 & 0.693 & 0.718 & 0.762 & 0.734 \\
$\mathrm{M}-\mathrm{P} \& \mathrm{O}$ & 0.578 & 0.486 & 0.619 & 0.695 & 0.719 & 0.764 & 0.734 \\
ANFIS & 0.579 & 0.490 & 0.621 & 0.697 & 0.721 & 0.767 & 0.740 \\
$\mathrm{CS}$ & 0.577 & 0.487 & 0.618 & 0.694 & 0.718 & 0.762 & 0.733 \\
\hline
\end{tabular}

Table 7. Performance evaluation among proposed techniques in view of time response and oscillation

\begin{tabular}{ccccccccc}
\hline inputs & $\mathrm{G}\left(\mathrm{W} / \mathrm{m}^{2}\right)$ & 700 & 500 & 800 & 1000 & 1000 & 1000 & 1000 \\
MPPT & $\mathrm{T}\left({ }^{\circ} \mathrm{C}\right)$ & 25 & 25 & 25 & 25 & 40 & 65 & 50 \\
\hline \multirow{2}{*}{ P\&O } & Tracking Time (s) & 0.023 & 0.013 & 0.009 & 0.007 & 0.005 & 0.006 & 0.006 \\
& Oscillation & high & high & high & High & high & high & high \\
& Tracking Time (s) & 0.025 & 0.017 & 0.016 & 0.014 & 0.007 & 0.015 & 0.011 \\
INC & Oscillation & high & high & medium & Medium & low & low & low \\
& Tracking Time (s) & 0.014 & 0.008 & 0.007 & 0.005 & 0.005 & 0.005 & 0.005 \\
FLC & Oscillation & high & low & medium & High & low & medium & low \\
& Tracking Time (s) & 0.015 & 0.002 & 0.004 & 0.003 & 0.004 & 0.005 & 0.003 \\
ANN & Oscillation & none & none & none & none & none & none & none \\
& Tracking Time (s) & 0.024 & 0.034 & 0.014 & 0.013 & 0.005 & 0.003 & 0.008 \\
M-P\&O & Oscillation & none & none & none & none & none & none & none \\
& Tracking Time (s) & 0.011 & 0.012 & 0.008 & 0.003 & 0.004 & 0.004 & 0.005 \\
ANFIS & Oscillation & high & medium & high & high & high & high & High \\
& Tracking Time (s) & 0.015 & 0.002 & 0.004 & 0.003 & 0.004 & 0.005 & 0.003 \\
CS & Oscillation & none & none & none & none & none & none & none \\
\hline
\end{tabular}


Table 8. Total cost and computing time comparison among MPPT proposed techniques

\begin{tabular}{|c|c|c|c|c|c|c|}
\hline \multirow{2}{*}{$\begin{array}{c}\text { MPPT } \\
\text { technique }\end{array}$} & \multicolumn{2}{|c|}{ Hardware Implementation } & \multirow{2}{*}{$\begin{array}{c}\text { Software } \\
\text { complexity }\end{array}$} & \multirow{2}{*}{$\begin{array}{c}\text { Sensed } \\
\text { parameters }\end{array}$} & \multirow[t]{2}{*}{ Cost } & \multirow{2}{*}{$\begin{array}{l}\text { Computing } \\
\text { Time (h) }\end{array}$} \\
\hline & Type & Complexity & & & & \\
\hline $\mathrm{P} \& \mathrm{O}$ & analog or digital & medium & medium & $\mathrm{V}, \mathrm{I}$ & low & 00:00:45-Fast \\
\hline INC & digital & complex & medium & $\mathrm{V}, \mathrm{I}$ & medium & 00:00:44-Fast \\
\hline FLC & digital & complex & high & $\mathrm{V}, \mathrm{I}$ & medium & 00:02:30-Slow \\
\hline ANN & digital & complex & medium & $\mathrm{G}, \mathrm{T}$ & high & 00:00:47-Fast \\
\hline M-P\&O & digital & complex & high & V, I & medium & 00:02:00-Slow \\
\hline ANFIS & digital & complex & high & $\mathrm{G}, \mathrm{T}, \mathrm{I}$ & high & 00:01:45-Slow \\
\hline $\mathrm{CS}$ & digital & complex & medium & $\mathrm{V}, \mathrm{I}$ & medium & 00:00:37-Fast \\
\hline
\end{tabular}

\section{CONCLUSION}

In this paper, a comparative study based MPPT is introduced for a stand-alone PV system modeled using MATLAB/SIMULINK program which contains (PV array, DC/DC buck converter controlled by MPPT controller, and resistive load). Based on simulation results and discussion in this work, operation of the PV system without any controller has low efficiency due to wrong variation of the operating point leading to power loss about 50\%. Seven MPPT controllers (P\&O, INC, FLC, ANN, ANFIS, M-P\&O, and CS) are proposed to overcome this problem. Comparison results between these controllers support the effectiveness and advantages of the proposed techniques, and it contains the following. The ANFIS based AI-techniques combines the functions for both FLC \& ANN, so it has the highest efficiency, but it requires additional sensor leading to higher implementation cost over the other techniques. Results of the CS based on metaheuristic techniques is similar to the ANN based on artificial intelligence where they produce ideal duty cycle and they have high tracking, no oscillation, high efficiency, but CS provided a significant advantage over others in view of low implementation cost, and fast computing time. The CS is the best technique and provides the best performance compared to other proposed techniques in this paper. The operation of M-P\&O with variable step-size using fuzzy controller eliminates the $\mathrm{P} \& \mathrm{O}$ high oscillation. The computing time depends on the software complexity, so FLC requires the longest time because selected membership functions increase the complexity. The implementation cost depends on number and type of required sensors, so techniques based on irradiance and temperature sensors are more expensive than others.

\section{APPENDIX}
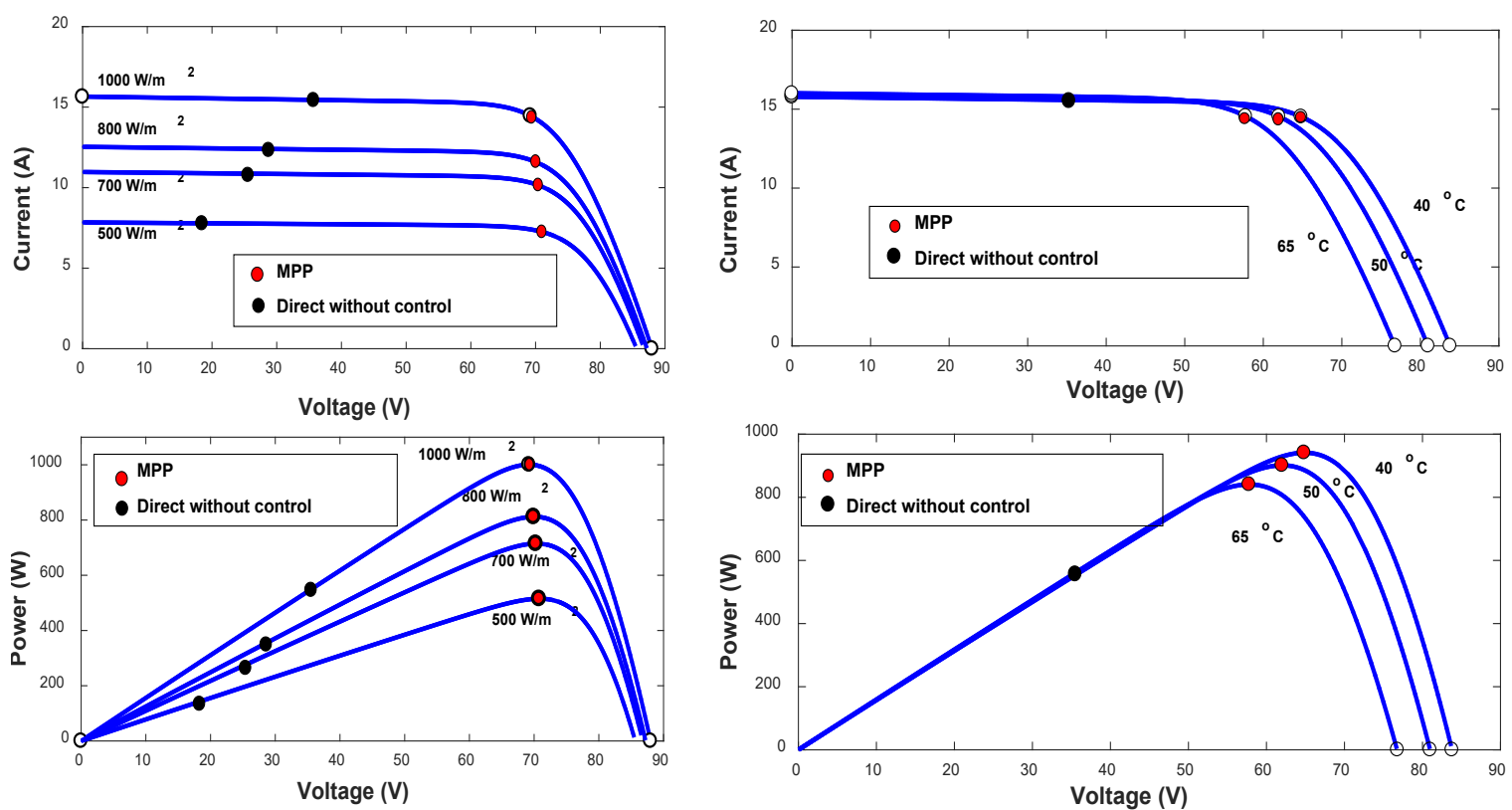

Figure 12. Operating points without MPPT on I-V \& P-V curves under different weather conditions 

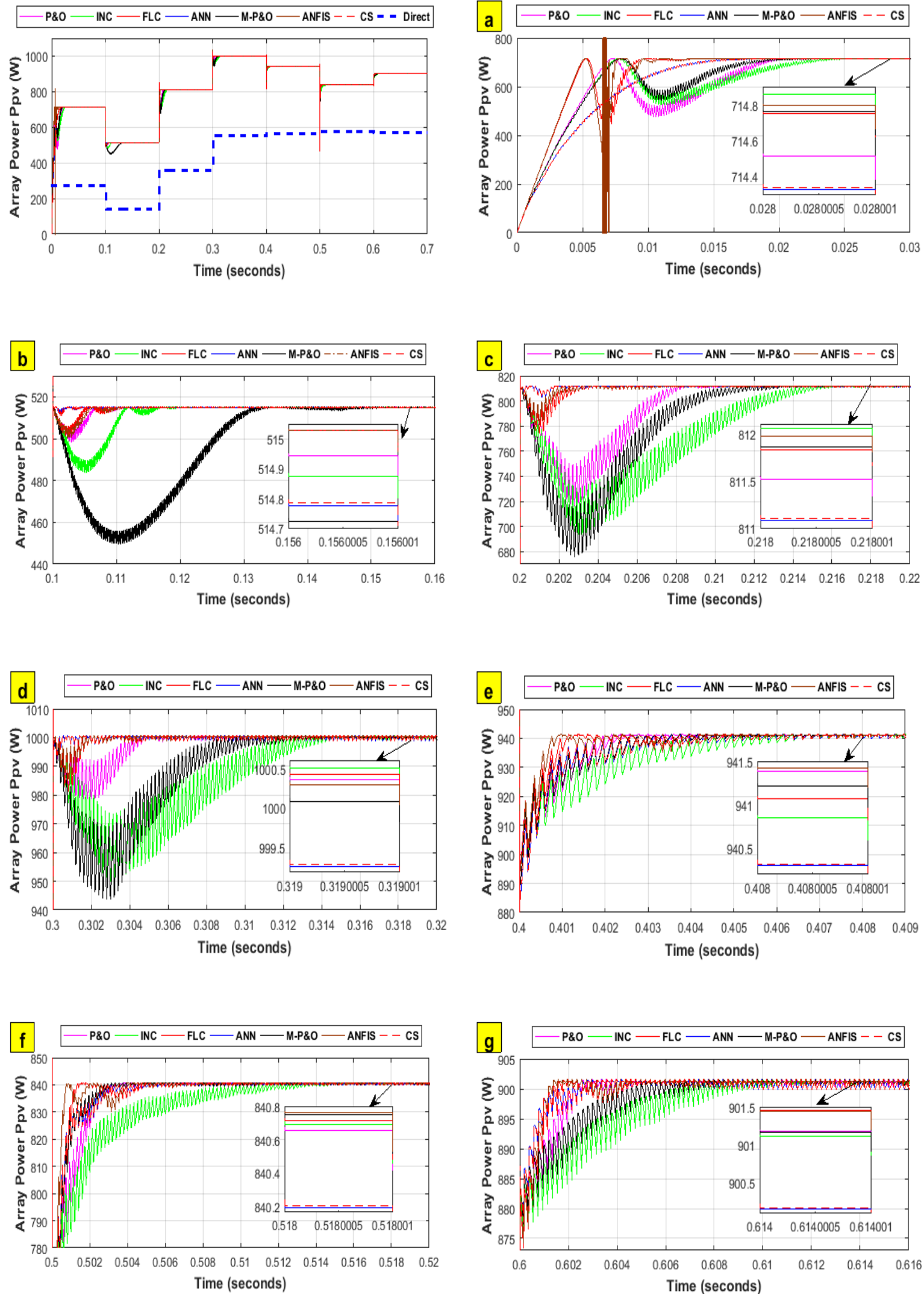

Figure 13. PV array power waveforms at steady-state and dynamic-state for proposed techniques 

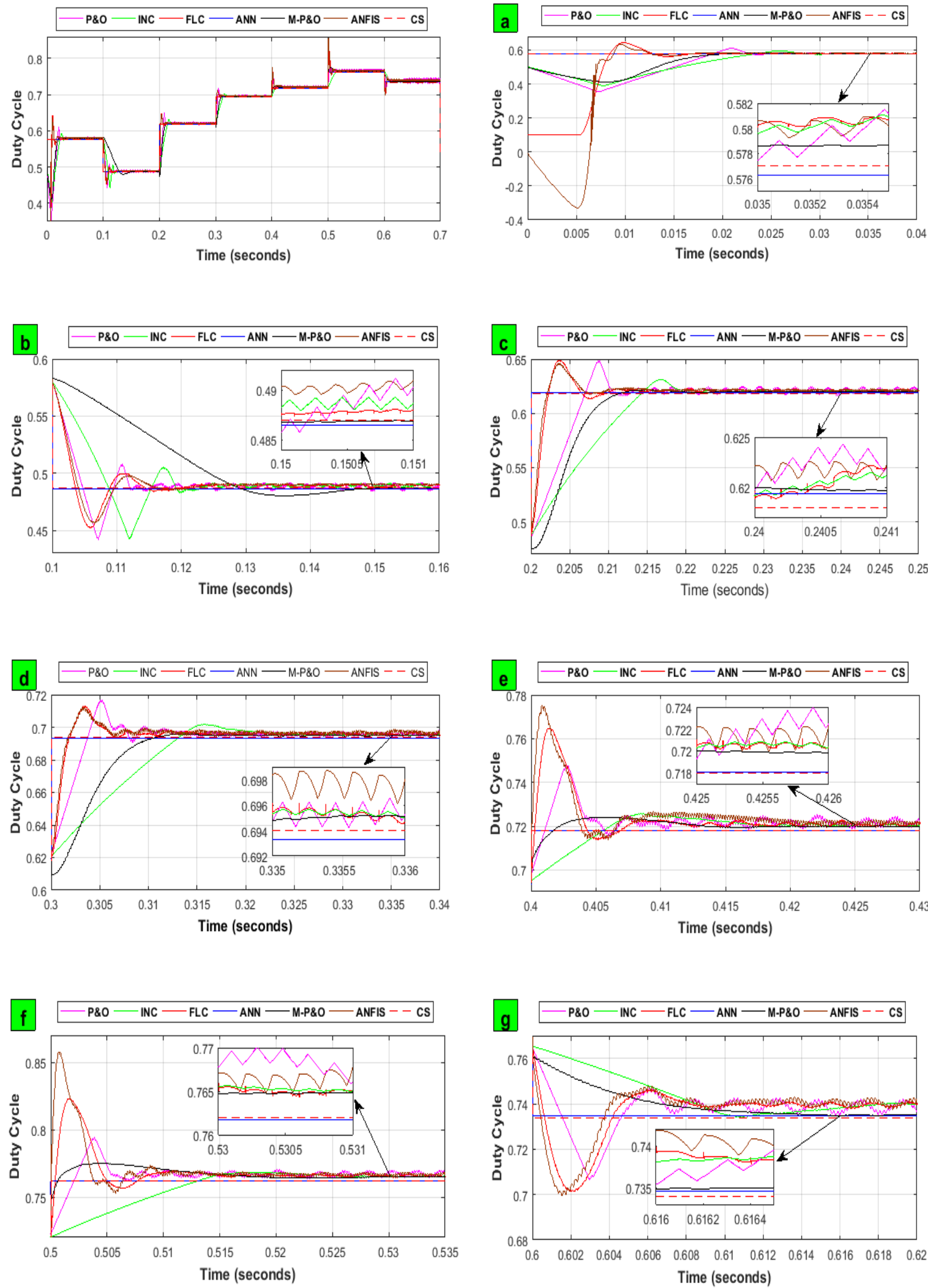

Figure 14. Duty ratio waveforms at steady-state \& dynamic-state for proposed techniques at seven periods 

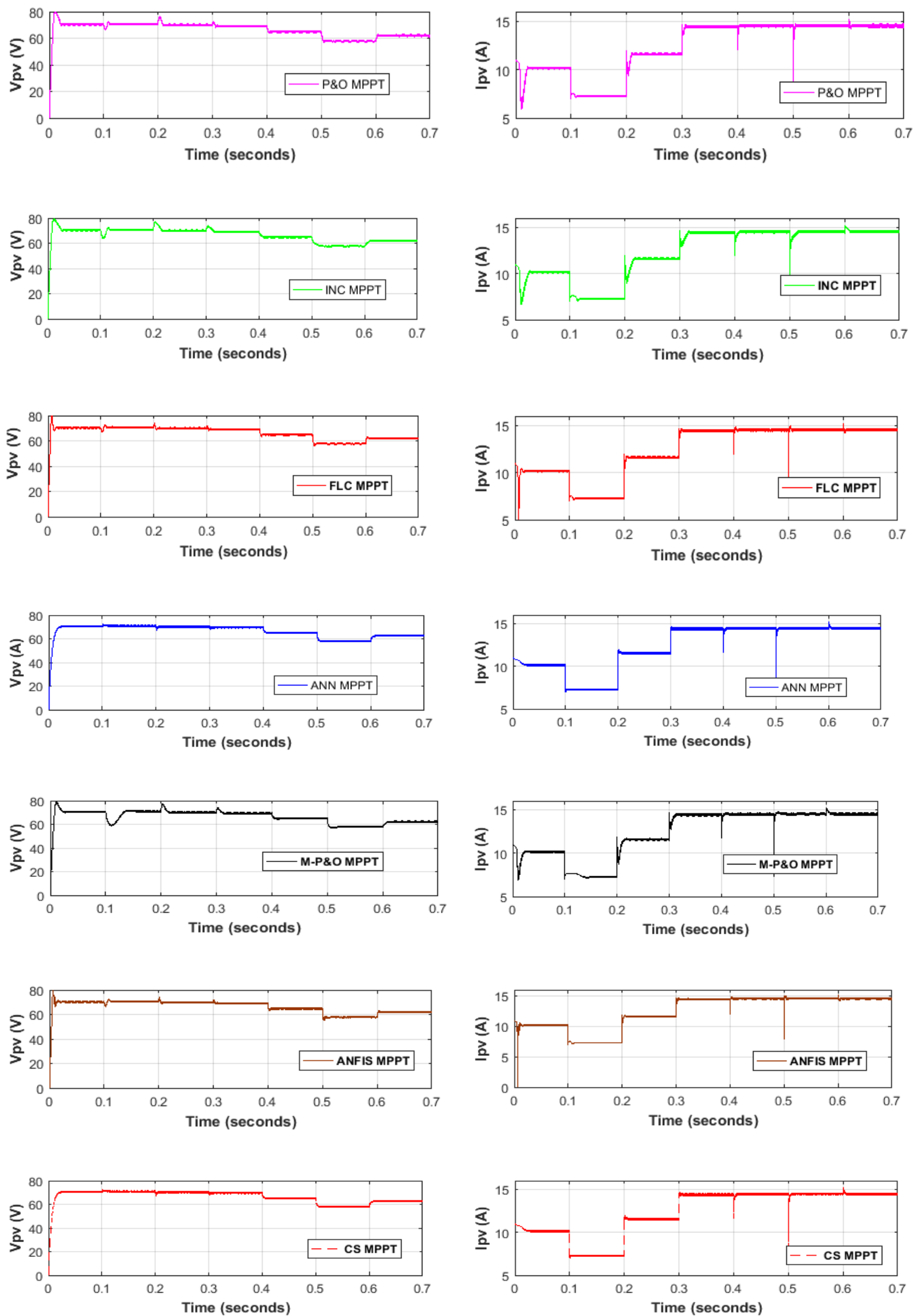

Figure 15. Waveforms of array voltage and current for proposed techniques 


\section{ACKNOWLEDGEMENTS}

The authors declare that they have no known competing financial interests or personal relationships that could have appeared to influence the work reported in this paper.

\section{REFERENCES}

[1] Yiwang Wang, Yong Yang, Gang Fang, Bo Zhang, Huiqing Wen, Houjun Tang, Li Fu, Xiaogao Chen, "An Advanced Maximum Power Point Tracking Method for Photovoltaic Systems by Using Variable Universe Fuzzy Logic Control Considering Temperature Variability," in Electronics, vol. 7, no. 12, 2018.

[2] Hegazy Rezk, El-Sayed Hasaneen, "A new MATLAB/Simulink model of triple-junction solar cell and MPPT based on artificial neural networks for photovoltaic energy systems," in Ain Shams Engineering Journal, vol. 6, no. 3, pp. 873-881, 2015.

[3] B. Bendib, F. Krim, H. Belmili, M.F. Almi, S. Boulouma, "Advanced Fuzzy MPPT Controller for a Stand-alone PV System," in Energy Procedia, vol. 50, pp. 383-392, 2014.

[4] Mingxuan Mao, Lichuang Cui, Qianjin Zhang, Ke Guo, Lin Zhou, Han Huang, "Classification and summarization of solar photovoltaic MPPT techniques: A review based on traditional and intelligent control strategies," in Energy Reports, vol. 6, pp. 1312-1327, 2020 .

[5] Ali Omar Baba, Guangyu Liu, Xiaohui Chen, "Classification and Evaluation Review of Maximum Power Point Tracking Methods," in Sustainable Futures, vol. 2, 2020.

[6] Bennacer El Hassouni, A. Haddi, A.G. Amrani, "Critical Study of Several MPPT Techniques for Photovoltaic Systems," Journal of Mechatronics and Robotics, vol. 3, no. 1, pp. 269-279, 2019.

[7] Mohammed Alsumiri, "Residual Incremental Conductance Based Nonparametric MPPT Control for Solar Photovoltaic Energy Conversion System," IEEE Access, vol. 7, pp. 87901-87906, 2019.

[8] Saad Motahhir, Abdelaziz El Ghzizal, Souad Sebti, Aziz Derouich, "Modeling of Photovoltaic System with Modified Incremental Conductance Algorithm for Fast Changes of Irradiance," International Journal of Photoenergy, vol. 2018, pp. 1-13, 2018.

[9] Carlos Robles Algarín, John Taborda Giraldo, Omar Rodríguez Álvarez, "Fuzzy Logic Based MPPT Controller for a PV System," in Energies, vol. 10, no. 12, 2017.

[10] Haitham Hassan, Mostafa Abdel Geliel, Mahmoud Abu-Zeid, "A proposed fuzzy controller for MPPT of a photovoltaic system," in 2014 IEEE Conference on Energy Conversion (CENCON), Johor Bahru, pp. 164-169, 2014

[11] E N Yaqin, A G Abdullah, D L Hakim, A B D Nandiyanto, "MPPT based on Fuzzy Logic Controller for Photovoltaic System using PSIM and Simulink," in IOP Conference Series: Materials Science and Engineering, vol. 288, 2018.

[12] Nabila Ghedhab, Fatiha Youcefettoumi, Abdelhamid Loukriz, Allaeddine Jouama, "Maximum Power Point tracking for a stand-alone photovoltaic system using Artificial Neural Network," in E3S Web of Conferences vol. 152, 2020.

[13] Lina M. Elobaid, Ahmed K. Abdelsalam, Ezeldin E. Zakzouk, "Artificial neural network-based photovoltaic maximum power point tracking techniques: a survey," in IET Renewable Power Generation, vol. 9, no. 8, pp. 1043-1063, 2015.

[14] Sadeq D. Al-Majidi, Maysam F. Abbod, Hamed S. Al-Raweshidy, "Design of an Efficient Maximum Power Point Tracker Based on ANFIS Using an Experimental Photovoltaic System Data," in Electronics, vol. 8, no. 8, 2019.

[15] Hichem Hamdi, Chiheb Ben Regaya, Abderrahmen Zaafouri, "A sliding-neural network control of induction-motorpump supplied by photovoltaic generator," in Protection and Control of Modern Power Systems, vol. 5, no. 1, 2020.

[16] M. A. Abido, M. Sheraz Khalid, Muhammed Y. Worku, "An Efficient ANFIS-Based PI Controller for Maximum Power Point Tracking of PV Systems," in Arabian Journal for Science and Engineering, vol. 40, no. 9, pp. 2641-2651, 2015.

[17] F. A. O. Aashoor and F. V. P. Robinson, "A variable step size perturb and observe algorithm for photovoltaic maximum power point tracking," in 2012 47th International Universities Power Engineering Conference (UPEC), London, pp. 1-6, 2012.

[18] Mohamed Rezoug, Rachid Chenni, Djamel Taibi, "Fuzzy Logic-Based Perturb and Observe Algorithm with Variable Step of a Reference Voltage for Solar Permanent Magnet Synchronous Motor Drive System Fed by Direct-Connected Photovoltaic Array," in Energies, vol. 11, no. 2, 2018.

[19] Mohamed I. Mosaad, M. Osama abed el-Raouf, Mahmoud A. Al-Ahmar, Fahd A. Banakher, "Maximum Power Point Tracking of PV system Based Cuckoo Search Algorithm; review and comparison," in Energy Procedia, vol. 162, pp. 117-126, 2019.

[20] Ahmed Ibrahim, Sergey Obukhov, Raef Aboelsaud, "Determination of Global Maximum Power Point Tracking of PV under Partial Shading Using Cuckoo Search Algorithm," in Applied Solar Energy, vol. 55, no. 6, pp. 367-375, 2019.

[21] Carlos Robles Algarín, Deimer Sevilla Hernández, Diego Restrepo Leal, "A Low-Cost Maximum Power Point Tracking System Based on Neural Network Inverse Model Controller," in Electronics, vol. 7, no. 1, 2018.

[22] Mustapha Elyaqouti, Safa Hakim, Sadik Farhat, Lahoussine Bouhouch, Ahmed Ihlal, "Implementation in Arduino of MPPT Using Variable Step Size P\&O Algorithm in PV Installations," in International Journal of Power Electronics and Drive Systems (IJPEDS), vol. 8, no. 1, pp. 434-443, 2017.

[23] Carlos Robles Algarín, Roberto Liñán Fuentes, Adalberto Ospino Castro, "Implementation of a cost-effective fuzzy MPPT controller on the Arduino board," in International Journal on Smart Sensing and Intelligent Systems, vol. 11, no. 1,pp. 1-10, 2018

[24] Guiza Dhaouadi, Ounnas Djamel, Soufi Youcef, Chenikhe Salah, "Implementation of Incremental Conductance Based MPPT Algorithm for Photovoltaic System," in 2019 4th International Conference on Power Electronics and their Applications (ICPEA), Elazig, Turkey, pp. 1-5, 2019. 
[25] Belhachemi Abdelkader, "Modeling and control of photovoltaic system using sliding mode controle, comparative studies with conventional controls," in Przeglad Elektrotechniczny, vol. 1, no. 2, pp. 184-189, 2020.

[26] Mostefa Kermadi, El Madjid Berkouk, "Artificial intelligence-based maximum power point tracking controllers for Photovoltaic systems: Comparative study," in Renewable and Sustainable Energy Reviews, vol. 69, pp. 369-386, 2017.

[27] Hegazy Rezk, Ali M. Eltamaly, "A comprehensive comparison of different MPPT techniques for photovoltaic systems," in Solar Energy, vol. 112, pp. 1-11, 2015.

[28] Hegazy Rezk, Ahmed Fathy, Almoataz Y. Abdelaziz, "A comparison of different global MPPT techniques based on meta-heuristic algorithms for photovoltaic system subjected to partial shading conditions," in Renewable and Sustainable Energy Reviews, vol. 74, pp. 377-386, 2017.

[29] CH Hussaian Basha, C Rani, "Different Conventional and Soft Computing MPPT Techniques for Solar PV Systems with High Step-Up Boost Converters: A Comprehensive Analysis," in Energies, vol. 13, no. 2, 2020.

[30] Byamakesh Nayak, Alivarani Mohapatra, Kanungo Barada Mohanty, "Selection criteria of dc-dc converter and control variable for MPPT of PV system utilized in heating and cooking applications," in Cogent Engineering, vol. 4 , no. 1, 2017.

[31] Osisioma Ezinwanne, Fu Zhongwen, Li Zhijun, "Energy Performance and Cost Comparison of MPPT Techniques for Photovoltaics and other Applications," in Energy Procedia, vol. 107, pp. 297-303, 2017

\section{BIOGRAPHIES OF AUTHORS}
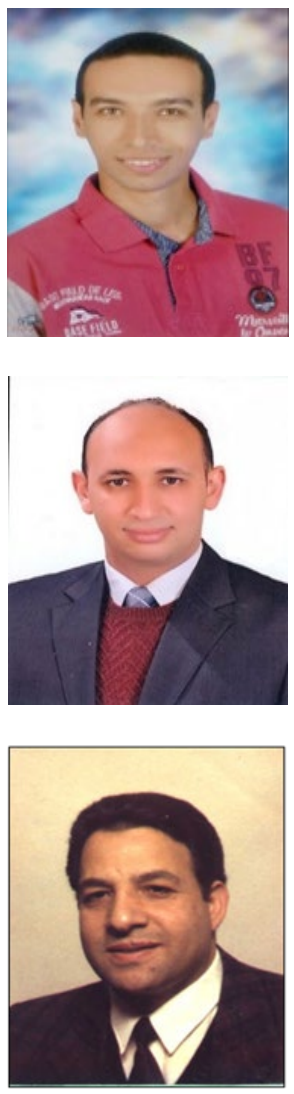

Mostafa Abd-Almoneam Abd-Alaleem Abosennah was born in Damanhur, Egypt, in 1990 He holds a bachelor's degree in electrical engineering (Power \& Machine) from Al-Azhar University, Qena, Egypt in 2013. He is presently working as Teaching Assistant in Electrical Engineering Department, Al-Azhar University, Qena, Egypt. His research, in the context of master thesis, focuses on the Maximum Power Point Tracking.

Dr. Mahmoud Abbas El-Dabah was born at Kafr-Elsheikh in 1985. He received a B.Sc., M.Sc., and Ph.D. degrees from Faculty of Engineering - AL-AZHAR University in Egypt in 2007, 2012, and 2016, respectively. $\mathrm{He}$ is an Associate Professor with the Electrical Engineering Department, Faculty of Engineering, AL-AZHAR University, Cairo, Egypt. His research interests involve power system operation, control, and planning, applications of modern optimization techniques in electric power systems, Renewable Energy Sources, Power system stability and Distributed Power Generation.

Dr. A. El-Biomey Mansour was born in Sanafa, Dakahlia, Egypt at 05.01.1946. He received his B.Sc. with honor degree in 1971 and M.Sc. degree in 1975 from the Electrical Engineering Department, Al-Azhar University, Cairo, Egypt. In 09.1981 he received an egyptian scholarship to get the degree of Doctor Engineering in West Germany. From 1983 to 1990, he got his Ph.D. in Automatic Control Systems from the group of Automatic Control and Technical Cybernetics in Wuppertal University, Germany. From 1986 to 1991 he worked as a scientific assistant in the group of Automatic Control and Technical Cybernetics in Wuppertal University, Germany. From 1991 to 2007 he worked as an assistant professor at Electrical Engineering Department, Al-Azhar University, Cairo, Egypt. In 2007, he was promoted to Associate Professor at Electrical Engineering Department, Al-Azhar University, Cairo, Egypt. Since 10.1998, he was a Delegated Lecturer at the Higher Technological Institute, Ramadan Tenth City in the fields, Industrial Process Control, Automatic and Digital Control Systems. Since 1991, he supervised more than 30 M.Sc and Ph.D. dissertations in the area of Automatic Control Systems including: Electric Power Control System, Robot Control System, Soler Energy Control System, Satellite Control System, Flight Control System, as well as he authored more than 40 papers. From summer 2005 to 2007 he provided specialized training sessions to Electrical Engineers, coming from different companies in the Middle East, in various reputable training centers (Arab Consulting and Development Corporation (ACAD), International Expertise Association (INTEX)). Those sessions include Transmission-and Distribution Networks (analysis and design), Fault Analysis, Power Flow and Stability, Voltage and Active/Reactive Power Control of Electrical Power Systems, Power Quality and Harmonics in Power Systems, and Design and Troubleshooting of Uninterruptible Power Supply (UPS). 